\title{
Microstructures and mechanical properties of graphene platelets-reinforced spark plasma sintered tantalum diboride-silicon carbide composites
}

\author{
Kübra GÜRCAN ${ }^{a^{*}}$ Ezgi İNCİ ${ }^{b}$, İbrahim SAÇKAN ${ }^{c}$, Erhan AYAS ${ }^{a}$, Hakan GAŞAN \\ ${ }^{a}$ Department of Material Science\&Engineering, Eskişehir Technical University, 26480, \\ Eskişehir/Turkey \\ ${ }^{\mathrm{b}}$ Department of Material Science\&Engineering, İzmir Institute of Technology, 35430, İzmir, Turkey \\ ${ }^{\mathrm{c}}$ DemirDöküm, Vaillant Group, 11300 Bilecik/Turkey \\ ${ }^{\mathrm{d} D e p a r t m e n t ~ o f ~ M e t a l l u r g y ~ a n d ~ M a t e r i a l s ~ E n g i n e e r i n g, ~ O s m a n g a z i ~ U n i v e r s i t y, ~ 26040, ~ E s k i s e h i r, ~}$
} Turkey

\begin{abstract}
Graphene nanoplates reinforcement (GNPs) $\mathrm{TaB}_{2}-\mathrm{SiC}$ composites were fabricated with Spark Plazma sintering (SPS) at $1850^{\circ} \mathrm{C}$ with a-uniaxial pressure of $50 \mathrm{MPa}$ and $10 \mathrm{~min}$ dwell time. Systematic investigation on the effect of GNP amount ofdensification, microstructural and mechanical properties (microhardness and fracture toughness) of the composites were presented. Density and hardness of composites decreased with the addition of GNP, while $~ 35 \%$ increase of fracture toughness value was obtained with GNP addition. The microstructural evaluation indicated that overlapped and agglomerated GNPs increased with an increasing amount of GNP in the composites and caused to decrease of density and hardness. On the other hand, GNP was retained in the composite form even with high process temperature $\left(1850^{\circ} \mathrm{C}\right)$ and cause toughening/of composites with changing the fracture mode from transgranular to transgranular/intergranular fracture. GNP pull out, crack branching, crack bridging and crack deflection were observed as main toughening mechanisms.
\end{abstract}

Keywords: UHTC, $\mathrm{TaB}_{2}$, Graphene, microfluidization, SPS.

Corresponding Author: kubragurcan@eskisehir.edu.tr

Tel: $+90(222) 3213550 / 7259$

Postal Address: Eskisehir Technical University, Iki Eylul Campus,

Department of Material Science and Engineering, 26480, Tepebaşi/ESKİSEHİR 


\section{Introduction}

$\mathrm{TaB}_{2}$ as a transition metal boride which belongs to ultra-high temperature ceramics have widespread high-performance applications due to their attractive combination of properties such as high melting point $\left(3200^{\circ} \mathrm{C}\right)$, high hardness $(>24 \mathrm{GPa})$, good corrosion resistance, excellent electrical and thermal conductivity, optical properties and other high temperature mechanical properties [1,2]. Due to these properties, $\mathrm{TaB}_{2}$ ceramics have received a great deal of potential owing to their applications in thermal potential components for the aerospace industry, absorber for solar energy systems/and refractory crucibles [3-6]. Only a few types of research have been carried out so far to tantalum diboride based materials, as extensively as other borides, though its excellent properties and potential application areas.

Although $\mathrm{TaB}_{2}$ have outstanding properties, its poor oxidation resistance and low mechanical properties restrict its usage in the monolithic form at higher temperatures $\left(>1200^{\circ} \mathrm{C}\right)$. Considering the potential application areas, especially improved fracture toughness and oxidation resistance properties play an integral role. In order to these, the addition of Si-based compositions ( $\mathrm{MoSi}_{2}, \mathrm{TaSi}_{2}, \mathrm{SiC}$, etc.) is the most widely used as secondary phase [7-10]. Further, different nanoscale carbon forms like carbon nanotubes (CNTs), graphene nanoplatelet (GNPs) addition is also prefered to improve fracture toughness of this material in recent years. Especially, graphene-based materials have more attention for the reinforcement of ceramics, due to their extraordinary thermal, electrical and mechanical properties [11-30]

Graphene is well known two-dimensional (2D) material which is an allotrope of carbon consisting of a single layer of strong in-plane covalent bonds between adjacent carbon atoms. Excellent high fracture strength $(125 \mathrm{GPa})$, high young modulus $(1 \mathrm{TPa})$, superior thermal conductivity $(5000 \mathrm{~W} / \mathrm{mK})$ properties, it is considered to be a popular candidate material as the second phase of ceramic matrix composites. Recently, there were many studies are obtained to focus on the addition of Graphene Platelets (GPL) in the ceramic matrix composites such as AlN [15-17] $\mathrm{Al}_{2} \mathrm{O}_{3}$ [19, 20], $\mathrm{Si}_{3} \mathrm{~N}_{4}$ [21-25], SiAlON [26]. Although GPL reinforced UHTC composites have recently studied due to the expected benefits -of GNP' remarkable properties [27-30] there are very few comprehensively investigations on the effect of GNP additives to enhance densification behavior andmechanical properties of UHTC composites. Govindaraajan et. all [27] stated that densification behavior of spark plasma sintered $\mathrm{ZrB}_{2}$ based ceramics was enhanced with the addition of $2-6 \% \mathrm{vol}$ graphene. They stated that crack deflection and crack bridging were the main toughening mechanisms to achieve higher fracture toughness values. Another graphene reinforced $\mathrm{ZrB}_{2}$-based ceramics study was carried out by Asl and Kakroudi with using hot pressing technique [28]. They stated that Vicker hardness and indentation fracture toughness values for the $5 \mathrm{wt} \%$ graphene platelets reinforced hot-pressed sample over the monolithic $\mathrm{ZrB}_{2}-25 \mathrm{vol} \% \mathrm{SiC}$ composite was increased up $30 \%$ and $250 \%$, respectively. In addition to crack bridging and crack deflection, graphene nano-platelets wrapping and pull out were also observed as a toughening 
mechanism. Akın and Kaya [29] fabricated $\mathrm{TiB}_{2}, \mathrm{TiB}_{2}-\mathrm{SiC}$ and $\mathrm{TiB}_{2}-\mathrm{SiC}-\mathrm{GNP}$ composites by using spark plasma sintering method in order to investigate the effects of binary and ternary composition different GPLs content on the density and mechanical properties of composites.

The density of $\mathrm{TiB}_{2}-\mathrm{SiC}$ and $\mathrm{TiB}_{2}$-SiC-GNP composites were calculated slightly higher in comparison to monolithic $\mathrm{TiB}_{2}$. Although the fracture toughness of $\mathrm{TiB}_{2}$ and $\mathrm{TiB}_{2}-\mathrm{SiC}$ composites showed an increasing tendency with the addition of 1,3 and $5 \%$ GNPs. The maximum fracture toughness obtained with the addition of $5 \%$ GNP which was calculated $6.4 \pm 0.4 \mathrm{MPa} \cdot \mathrm{m}^{1 / 2}$. While fracture toughness values raised with increasing GNP amount up to 5\%, it decreased with the addition of $7 \%$ and $10 \%$ GNP owing to the weak interfaces between the GNPs and matrix grains. Recently, Burak et all. [30] investigated the effects of GNPs addition between 0.5 and 9 vol\% on the fracture toughness of spark plasma sintered ZrC-TiC-GNP composites. They remarked that almost full dense ZrC-TiC-GNP composite and higher fracture toughness value were obtained with the addition of 3 vol\% GNP. Addition of more than $3 \% \mathrm{vol}$ GNP, density and mechanical properties of composites weredecreased owing to the graphene agglomeration. All these results are convenient with not only for GNP reinforced UHTC ceramics but also GNP-reinforced ceramics like $\mathrm{Si}_{3} \mathrm{~N}_{4}, \mathrm{Al}_{2} \mathrm{O}_{3}, \mathrm{SiAlON}$, AlN[15-26].

Although graphene addition enhances the densification and mechanical properties clustering of individual GNP's plays an important role affecting the density and properties of formed composites. GNPs were generally homogenized with milling [18, 20-22] sonication and ultrasonication [16, 23-25] techniques with/without mixing with other composite powders in the literature. However, these techniques were found to be insufficient to break the weak Wan der Waals bonds between platelets and provide less clustered GNP's. Different from sonication and ultrasonication recently, exfoliation techniques such sonication-microfluidization [26] was investigated and reported that this process was more effective for the exfoliation of GNP's. It was also remarked that smaller matrix grain size was obtained in the microstructure due to smaller platelet sizes and much narrower GNP thickness distribution.

Microfluidization technique which was also used firstly for hexagonal boron nitride exfoliation [31] generates extremely high pressures (up to $207 \mathrm{MPa}$ ). This high pressure is utilized to accelerate the liquid product into the interaction chamber with the high velocities (up to $500 \mathrm{~m} / \mathrm{s}$ ). constant high pressure and higher velocities, the energy was converted more efficiently into shear and impact forcewhich leads to achieve reduction in nano-particle size and narrow particle size distribution. .

Considering the literature, the homogeneous dispersion of GNPs into the matrix has an important role to produce composites with improved properties. In this purpose, the original aspect of this study was to investigate the effects of GNP addition on the densification, microstructural and mechanical 
properties of spark plasma sintered $\mathrm{TaB}_{2}-20 \mathrm{vol} \% \mathrm{SiC}$. According to the literature results, exfoliation of GNP's was prepared with the microfluidization-sonication process. The results of this study can make new contributions to the current literature as the first results of a novel process which allows the production of homogeneously distributed GNP's reinforced UHTC composites thanks to the microfluidization-sonication process.

\section{Materials and Methods}

\subsection{Powder Preparation and Sintering Parameters}

The composition was prepared by using as-synthesized $\mathrm{TaB}_{2}$ [32] and 20 vol \% $\mathrm{SiC}$ (HC-Starck Grade UF-15) and graphene nanoplatelets (GNPs) (Graphene Chemical Industries Company, 99.9\% purity, $120-150 \mathrm{~m}^{2} / \mathrm{g}$ specific surface area, 5-8 $\mathrm{nm}$ thickness, $5 \mu \mathrm{m}$ average particle diameter). $\mathrm{TaB}_{2}-\mathrm{SiC}$ composites were mixed in a polythene bottle for $24 \mathrm{~h}$ with using $\mathrm{Si}_{3} \mathrm{~N}_{4}$ balls as milling medium. In order to break agglomerates, powder mixture sieved under $100 \mu \mathrm{m}$.

GNP was homogenized with microfluidization-sonication combined techniques. Before the microfluidization, tip sonication (Sonics, $750 \mathrm{Vef}$ ) was applied for 15 min with $16 \mathrm{~s}$ vibration and $25 \mathrm{~s}$ standby at the $20 \mathrm{kHz}$ frequency and $40 \%$ of amplitude condition. Liquid to GNP ratio of the slurry was selected as 400:1 (ml:g) for sonication process. Sonicated slurry was homogenized with high-pressure microfluidizer (Microfluidics Corp.) at a constant intensifier pump pressure of $207 \mathrm{MPa}$. To investigate the efficiency of microfluidization process after 4 cycle GNPs were investigated by scanning electron microscope (Zeiss, SUPRA 50 VP). Exfoliated GNP's were obtained after 16 cycle in microfluidization process. Detailed results were explained in results and discussion part.

After the microfluidization process 1,3 and $5 \mathrm{wt} \%$ of GNPs were mixed with $\mathrm{TaB}_{2}$-SiC composite with sonication process for $1 \mathrm{~h}$. During the sonication $0.5 \mathrm{wt} \%$ sodium dodecyl sulfate (SDS) was added as an anionic surfactant to prevent the agglomeration of the exfoliated GNPs. Then the powders were mixed in a planetary ball mill (Pulverisette, P6, Fritsch) in 2-propanol using $\mathrm{Si}_{3} \mathrm{~N}_{4}$ grinding media at $450 \mathrm{rpm}$ for $90 \mathrm{~min}$ and dried in a rotary evaporator (Heidolph) at $60^{\circ} \mathrm{C}$. To break up agglomerates; the powders were sieved under $100 \mu \mathrm{m}$. Sintering of composites was carried out in an SPS furnace (HPD$50, \mathrm{FCT} \mathrm{GmbH}$, Germany) at $1850^{\circ} \mathrm{C}$ under a uniaxial pressure of $50 \mathrm{MPa}$ for $10 \mathrm{~min}$. The heating rate was $100^{\circ} \mathrm{C} / \mathrm{min}$. The powders were put into a graphite die $20 \mathrm{~mm}$ in diameter and the die was covered with a graphite blanket for preventing heat loss. The temperature was increased with a controlled electric current and measured on the graphite die surface with an optical pyrometer. In order to evaluate the effects of GNPs addition on the densification, microstructural and mechanical properties, $\mathrm{TaB}_{2}-20 \% \mathrm{vol}$ $\mathrm{SiC}$ composites without GNP addition were also produced in the same conditions. 


\section{Results and Discussion}

\subsection{Morphology of Microfludized GNPs}

The SE-SEM images of untreated GNPs and GNP's prepared by using sonication and microfludization process with 4,8,12,16 times repetition were shown in Figure 1. Untreated GNP exhibited nonhomogeneous distribution and graphene platelets clusters which were shown in Fig 1.a. Partial exfoliation of GNP's was observed after the 4-times and 8-times repetition of microfluidization technique (Fig 1.b and 1.c). On the other hand a partial agglomeration was still observed in both micrographs. After 12 times repetition GNP's were more homogenized (Fig 1.d). When the repetition time increased to 16, it was clear that GNP's were much smaller and thinner. Considering these results, microfluidization process with 16 times repetition was found to be successful in terms of exfoliating and homogeneously distribute GNPs which also resulted size reduction.

\subsection{Microstructure of Produced Samples}

The bulk and relative density values of $\mathrm{TaB}_{2}-\mathrm{SiC}$ and GNP reinforced $\mathrm{TaB}_{2}-\mathrm{SiC}$ composites were given in Table 1. The bulk density of $\mathrm{TaB}_{2}-\mathrm{SiC}$ was calculated as $10.35 \mathrm{~g} / \mathrm{cm}^{3}$ which was approximately $97 \%$ of the theoretical limit for SPS'ed TaB $2-\mathrm{SiC}$ composites. The relative density of $1 \mathrm{wt} \%$ GNPs reinforced $\mathrm{TaB}_{2}-\mathrm{SiC}$ is $96.47 \%\left(10.33 \mathrm{~g} / \mathrm{cm}^{3}\right)$ and the density slight decreased further as GNPs content increased 

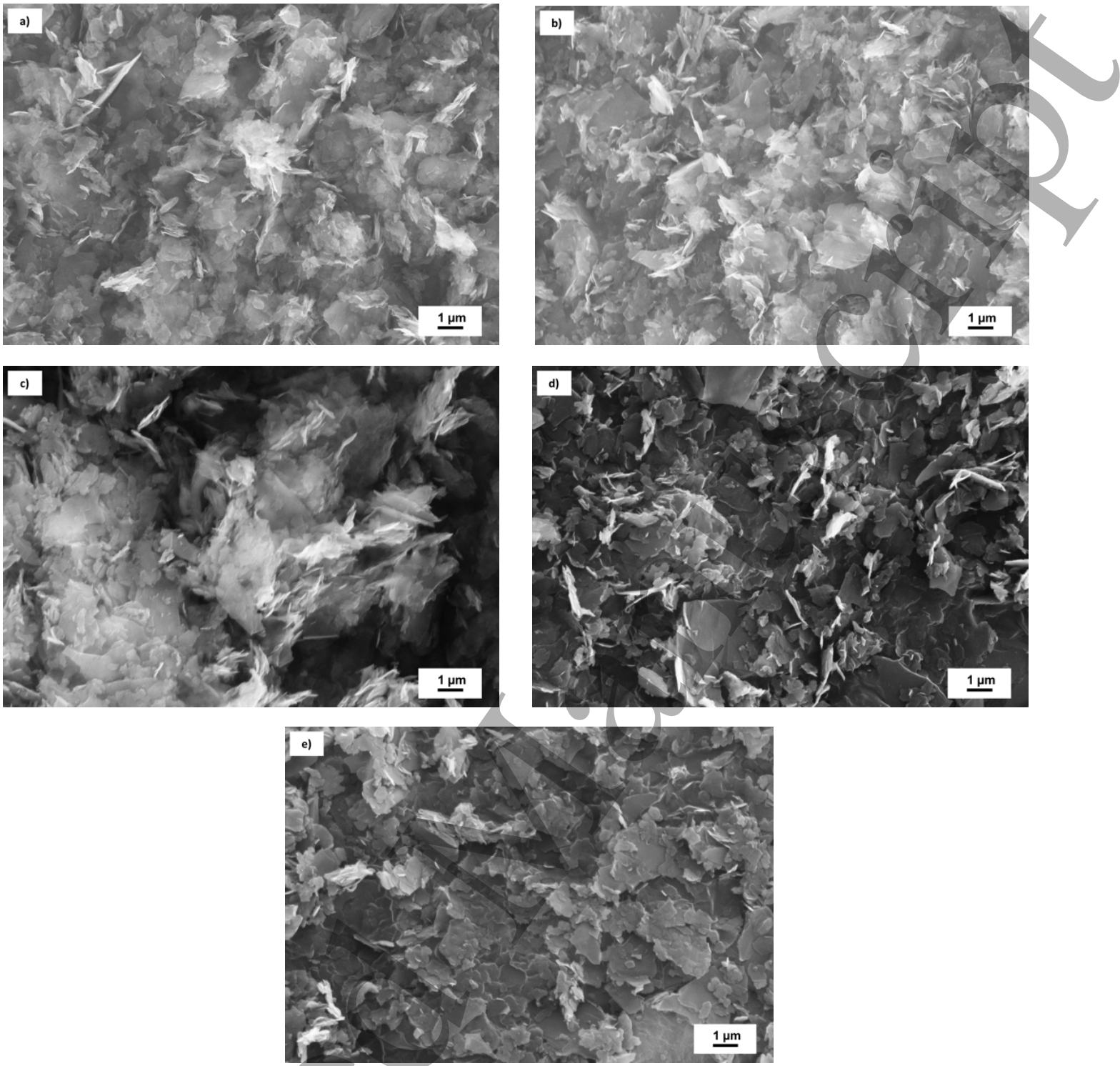

Figure 1. SE-SEM images showing the morphology of a) Untreated b) 4-times repetition c) 8-times repetition d) 12-times repetition and e) 16 times repetition GNPs with microfludizing technique.

to 3 and $5 \mathrm{wt} \%$. GNPs have a tendency of agglomerate with the increasing amount in the composites. The flexibility of the GNPs reduced by agglomeration and this could led to the formation of porosities at the interfaces between GNPs and $\mathrm{TaB}_{2}$ and $\mathrm{SiC}$ grains. Additionally, mismatch of thermal expansion coefficient between matrix and layered solids like graphene caused to crack of graphene layered and lead to the formation of porosities, so it could be another reason for obtaining lower density values. The decreasing density values of GNP reinforced composites was agreeable with the literature [16, 18, 21, $22,24,26]$. 
Table 1. Bulk and relative density of SPS' ed $\mathrm{TaB}_{2}-\mathrm{SiC}$ and $\mathrm{TaB}_{2}-\mathrm{SiC}$ matrix composites containing different amount of GNP

The comparison of SE-SEM images taken from the fracture surface of $\mathrm{TaB}_{2}$-SiC composites containing without and with 1, 3, $5 \mathrm{wt} \%$ GNPs was depicted in Figure 2. In all images, dark grey colored grains correspond to $\mathrm{SiC}$, while the grains in light grey color illustrates $\mathrm{TaB}_{2}$ grains. White-colored grains were also observed which are correspond to $\mathrm{TaC}$ grains. Observation of $\mathrm{TaC}$ grains was related to the $\mathrm{C}$ diffusion from the graphite crucible during the heat treatment process which was explained in our previous study [32]. It was clearly observed that the distribution of SiC particles and GNP's were not well-distributed in the microstructure which shown with yellow rectangular in Figure 2.a. Density difference between $\mathrm{TaB}_{2}, \mathrm{SiC}$ and graphene particles lead to the segregation of particles during the mixing process. Depending on the non-homogeneous distribution of particles, local sintered regions were observed in the especially GNP added samples. Inhomogeneous distribution of the additives in the matrix due to the segregation of particles was in agreement with related studies [34, 35]. As demonstrated in high magnification SEM micrographs (Figure 2.b), SiC was observed to locate in multiple grain interfaces, which inhibited $\mathrm{TaB}_{2}$ grain growth by pinning effect [36-38]. The appearance of GNP standing out from the fracture surfaces of the composites showed that GNPs formed network structures, despite the non-uniform distribution in the matrix. The GNPs wrapped around the matrix grains and conformed to the shapes of $\mathrm{TaB}_{2}, \mathrm{SiC}$, and $\mathrm{TaC}$ grain boundaries. Wrapped of graphene resulted in the formation of a finer microstructure due to the grain boundary movement induced by the GNPs during sintering. Besides the wrapped of GNPs, pulled-out (Figure 2.d.,f.,h.), overlapped (Figure 2.h.) and agglomerated (Figure 2.g.) GNPs and the separation of the matrix grains were clearly observed, especially at high concentrations of GNP (Figure 2.e.f.g.h.). It was also seen that intergranular fracture mode was predominant in the matrix grains. It was concluded with related studies [29, 39, 40] wrapping of GNP was positively affected for the strengthening of the composite. Another remarkable point in the SEM images that the size of $\mathrm{TaB}_{2}-\mathrm{SiC}$ matrix grains decreased with the addition of GNP's since the GNP inhibited the grain growth of the $\mathrm{TaB}_{2}$ and $\mathrm{SiC}$ grains during sintering. This result was also in agreement with the related studies [26]. 

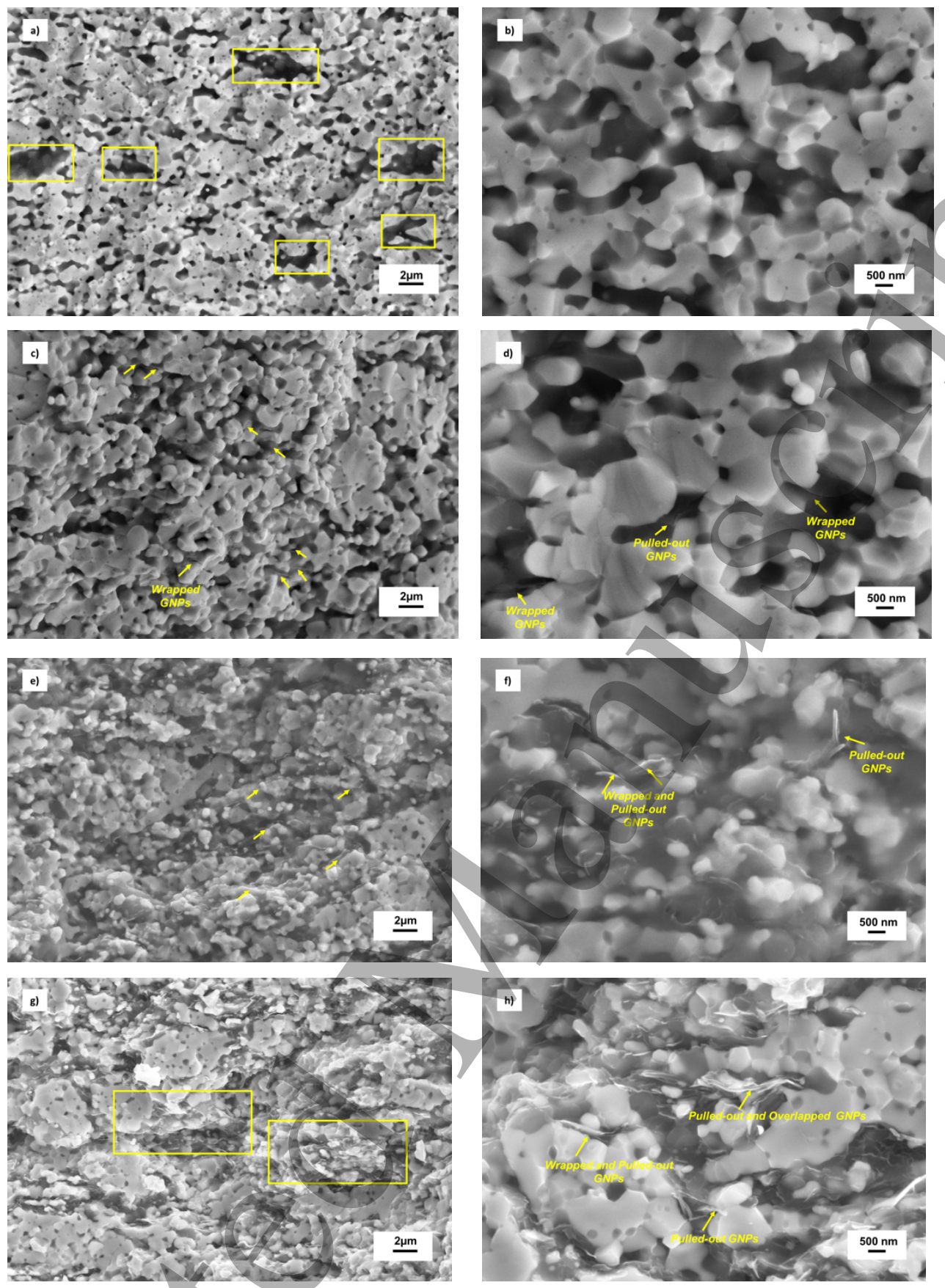

Figure 2. SE-SEM images of a)-b) $\mathrm{TaB}_{2}-\mathrm{SiC}$, c)-d) $\mathrm{TaB}_{2}-\mathrm{SiC}-1 \mathrm{GNP}$ e)-f) $\mathrm{TaB}_{2}-\mathrm{SiC}-3 \mathrm{GNP}$

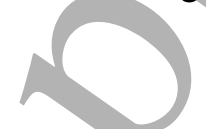

g)-h) $\mathrm{TaB}_{2}-\mathrm{SiC}-5 \mathrm{GNP}$ composites.

The Raman Analysis obtained from micro fluidized GNPs and also composites containing 1, 3 and 5 wt\% GNP were given in Table 2 and Figure 3. The characteristic peaks of graphene in Raman Spectroscopy were found D, G and 2D bands at approximately 1350, 1580 and $2700 \mathrm{~cm}^{-1}$ Raman shift. The modes corresponding to $\mathrm{G}$ peaks were attributed to stretching of the $\mathrm{C}-\mathrm{C}$ bond in graphitic materials and they were common to all $\mathrm{sp}^{2}$ carbon systems. D band was called as disorder or defects bands which were not observed in the perfect $\mathrm{sp}^{2}$ carbon systems. In addition, the $2 \mathrm{D}$ peak was named as the second order of D peak and caused by the double resonant Raman scattering with two-phonon emission [41, 
42]. Although shifting of the energy level of peaks, the single and sharp shape of characteristic peaks of GNPs were observed for the micro fluidized GNP. Changing the energy level of GNPs characteristic peaks were the results of increasing the number of graphene layers. With the formation of composite forms, peak broadening and decreasing of intensity exhibited, especially 2D-band peak. Also, it was clearly observed that 2D peak shifted to lower energy level, while D and G peaks shifted to the higher energy level in GNP added composites.

Table 2. Average $\mathrm{I}_{2 \mathrm{D}} / \mathrm{I}_{\mathrm{G}}$ and $\mathrm{I}_{\mathrm{D}} / \mathrm{I}_{\mathrm{G}}$ calculated by using at least five Raman measurement.

\begin{tabular}{ccc}
\hline Sample & Average $\mathrm{I}_{2 \mathrm{D}} / \mathrm{I}_{\mathrm{G}}$ & Average $\mathrm{I}_{\mathrm{D}} / \mathrm{I}_{\mathrm{G}}$ \\
\hline GNPs & 0,751 & 0,491 \\
$\mathrm{TaB}_{2}$-SiC-1GNP & 1,019 & 0,847 \\
$\mathrm{TaB}_{2}$-SiC-3GNP & 1,085 & 0,832 \\
$\mathrm{TaB}_{2}$-SiC-5GNP & 1,083 & 0,829 \\
\hline
\end{tabular}

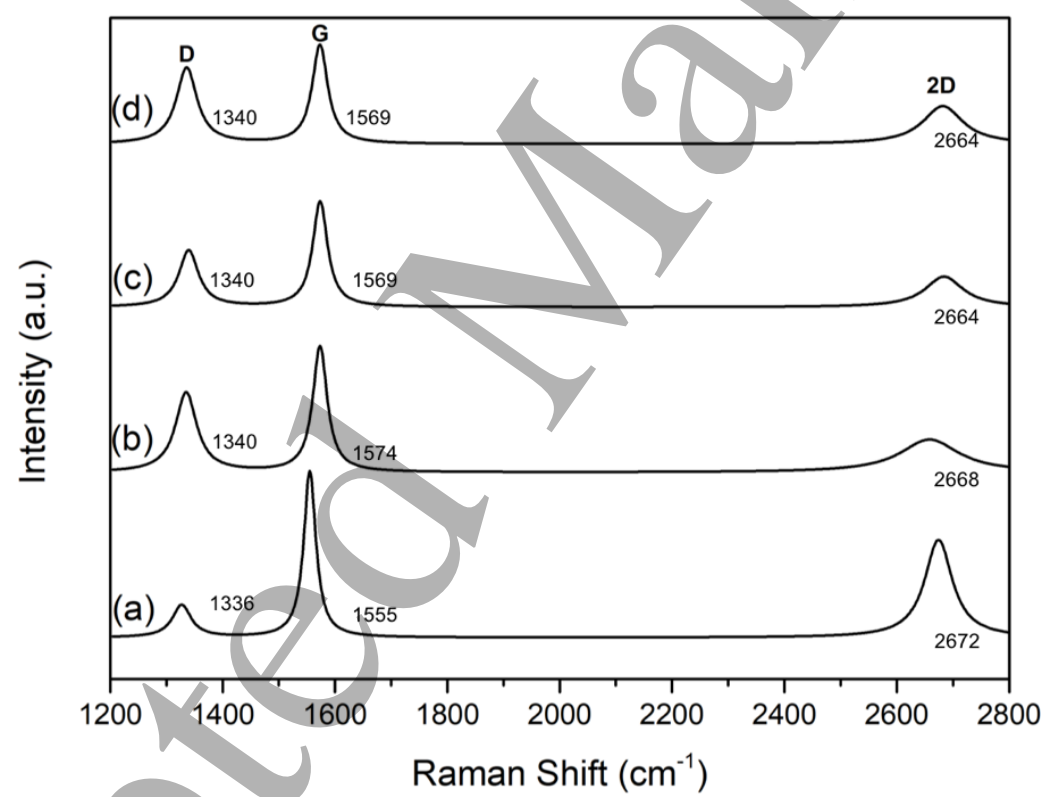

Figure 2. Raman spectra obtained from a) microfludized GNPs, b) TaB $2-\mathrm{SiC}-1 \mathrm{GNP}$, c) $\mathrm{TaB}_{2}-\mathrm{SiC}-$ 3 GNP and d) $\mathrm{TaB}_{2}-\mathrm{SiC}-5 \mathrm{GNP}$

Changing of position and decreasing of intensities of characteristic peaks were explained with density of defects during sintering process [26, 27, 43], uniaxial strain and residual thermal stresses during the cooling step[43] changing of the graphene layer amount and doping effect on the GNPs [27, 43]. Especially, doping of GNP with B atoms was the possible reason for the lower shift of 2D band which were reported in previous studies [27, 44]. Besides the doping effect of GNPs, a lower shift in the 2D band can be implied that the decreasing number of graphene layers[45]. As a matter of fact, the ratio of 
$\mathrm{I}_{2 \mathrm{D}} / \mathrm{I}_{\mathrm{G}}$ peak intensities has been commonly used the number of graphene layer [41, 42]. In the current study, at least five measurements were carried out for each sample and the average values of maximum peak intensity were determined (Table 2). For single-layer graphene, the intensity ratio $I_{2 D} / I_{G}$ was calculated as 2 [46]. The average $\mathrm{I}_{2 \mathrm{D}} / \mathrm{I}_{\mathrm{G}}$ ratio of micro fluidized GNPs was 0.751 so it indicated the multilayer graphene structure. Meanwhile, in the GNP added composites the average value of $\mathrm{I}_{2 \mathrm{D}} / \mathrm{I}_{\mathrm{G}}$ increased up to 1.085 which showed that thickness of some GNPs reduced. On the other hand, a slight decrease in the $\mathrm{I}_{2 \mathrm{D}} / \mathrm{I}_{\mathrm{G}}$ ratio was achieved at the $5 \mathrm{wt} \% \mathrm{GNP}$ added composite. This decrease could be explained due to the tendency of agglomeration of GNPs during powder preparation and sintering process.

Peak intensity of D band in the sintered composites was increased compared with the micro fluidized GNPs. (Fig 3.b.c.d.). The increased peak intensity was interpreted as a result of increasing defects or disorders in the crystal structure of GNPs. In order to determine the density of defects in graphene-based materials, measurement of the $\mathrm{I}_{\mathrm{D}} / \mathrm{I}_{\mathrm{G}}$ ratio was one of the basic methods [47]. The average $\mathrm{I}_{\mathrm{D}} / \mathrm{I}_{\mathrm{G}}$ ratio of the micro fluidized GNPs calculated as 0.491 . This value increased up to 0.847 in the composite form of the formed samples. It was explained with the interfacial reaction between GNPs and $\mathrm{TaB}_{2}-\mathrm{SiC}$ matrix at a higher sintering temperature $\left(1850^{\circ} \mathrm{C}\right)$ in SPS which were supported with relevant literature $[27$, 48]. Takai et all.[48] reported that the average crystallite size of nanocrystalline graphite increased with the applied high sintering temperature $\left(>1600^{\circ} \mathrm{C}\right)$. In light of this result, Yadhukulakrishnan et all.[27] showed the analyzed the $\mathrm{I}_{\mathrm{D}} / \mathrm{I}_{\mathrm{G}}$ ratio of sintered GNPs which was close to zero close to crystalline graphite. Also, the density of defects or disorders scaled inversely with the concentration of GNPs in the composite forms. The value of $\mathrm{I}_{\mathrm{D}} / \mathrm{I}_{\mathrm{G}}$ was calculated as 0.847 for $1 \mathrm{wt} \% \mathrm{GNP}$ reinforced $\mathrm{TaB}_{2}-\mathrm{SiC}$ composite, which was slightly higher than 3 and $5 \mathrm{wt} \%$ GNP reinforced $\mathrm{TaB}_{2}-\mathrm{SiC}$ composite. One possible reason was decreased agglomeration and more homogeneously distributed GNPs in the matrix, so more surface interaction between carbon and $\mathrm{TaB}_{2}-\mathrm{SiC}$ was provided. Yadhukulakrishnan et all. [27] also explained this result with the higher multiplication of GNPS, due to the exfoliation at lower GNP amount, but achieved results were very close to each other so, higher multiplications was not considered to be a high possibility.

XRD patterns obtained from the SPS'ed $\mathrm{TaB}_{2}-\mathrm{SiC}$ and $\mathrm{TaB}_{2}-\mathrm{SiC}$ matrix composites containing 1,3 and $5 \mathrm{wt} \%$ GNPs were illustrated in Figure 4. According to the results, $\mathrm{TaB}_{2}$ and $\mathrm{TaC}$ existed as a major crystalline phase. Remarkable point in this figure, intensity of $\mathrm{TaC}$ peak was increased with the addition of GNPs. As mentioned before, $\mathrm{TaC}$ formation was explained with the $\mathrm{C}$ diffusion from graphite crucible during the synthesis and sintering of $\mathrm{TaB}_{2}$ [32]. In addition, interaction between GNPs and $\mathrm{TaB}_{2}$ was thought to be another reason for the formation of TaC. Table 3 showed that the Rietveld analysis results based on the XRD patterns of $\mathrm{TaB}_{2}-\mathrm{SiC}, \mathrm{TaB}_{2}-\mathrm{SiC}-1 \mathrm{GNP}, \mathrm{TaB}_{2}-\mathrm{SiC}-3 \mathrm{GNP}$ and $\mathrm{TaB}_{2}-$ SiC-5GNP samples. Considering the calculated values, interaction between GNPs and $\mathrm{TaB}_{2}$ is the 
another possible reaction for the formation of $\mathrm{TaC}$, With the addition of $\% 1 \mathrm{wt}$ GNPs in the $\mathrm{TaB}_{2}-\mathrm{SiC}$ composite, amount of $\mathrm{TaC}$ increased from $8.82 \mathrm{wt} \%$ to 13.65 , while amount of $\mathrm{TaB}_{2}$ decreased from $89.75 \mathrm{wt} \%$ to $84.91 \mathrm{wt} \%$. It was observed that decrease in the amount of $\mathrm{TaB}_{2}$ continued with increasing of GNPs ratio. In addition to the decrease for $\mathrm{TaB}_{2}$ amount, a decrease in the amount of $\mathrm{TaC}$ was observed. This may be explain that a portion of graphene interacts with the $\mathrm{TaB}_{2}$ and formed $\mathrm{TaC}$.

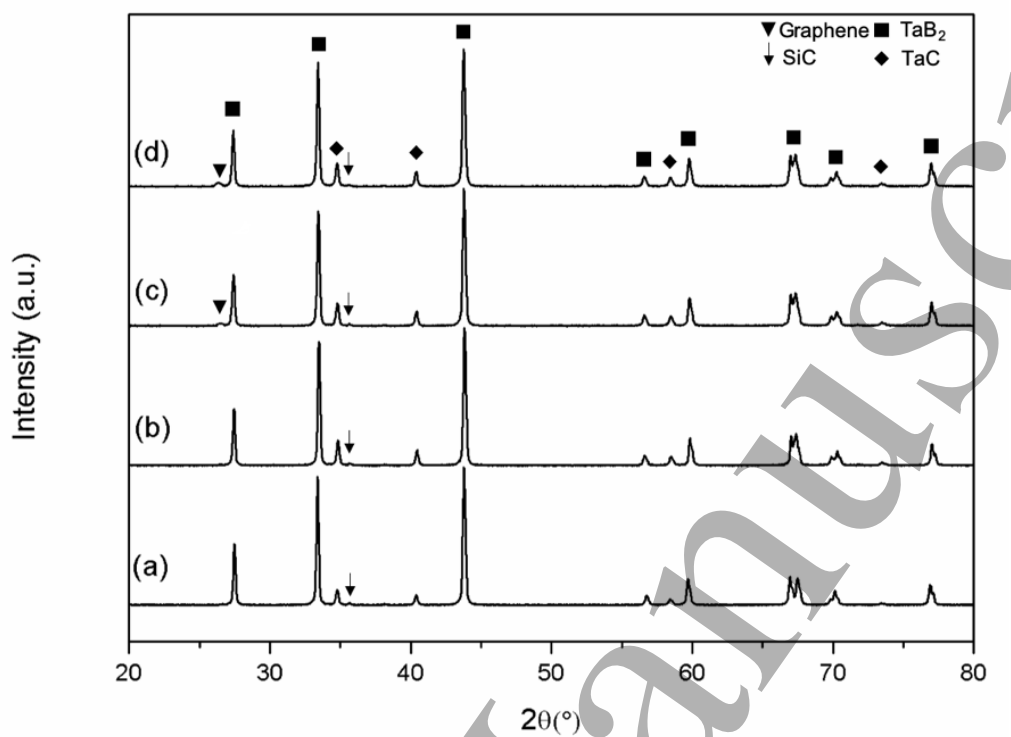

Figure 4. XRD patterns obtained from SPS'ed a) $\mathrm{TaB}_{2}-\mathrm{SiC}$ b) $\mathrm{TaB}_{2}-\mathrm{SiC}-1 \mathrm{GNP}$ c) $\mathrm{TaB}_{2}-\mathrm{SiC}-$ $3 \mathrm{GNP}$ d) $\mathrm{TaB}_{2}-\mathrm{SiC}-5 \mathrm{GNP}$

Table 3. Rietveld analysis results based on the XRD patterns of $\mathrm{TaB}_{2}-\mathrm{SiC}, \mathrm{TaB}_{2}-\mathrm{SiC}-1 \mathrm{GNP}$, $\mathrm{TaB}_{2}$-SiC-3GNP and $\mathrm{TaB}_{2}$-SiC-5GNP samples.

\begin{tabular}{ccccc}
\hline Sample & $\mathrm{TaB}_{2}(\mathrm{wt} \%)$ & $\mathrm{TaC}(\mathrm{wt} \%)$ & $\mathrm{SiC}(\mathrm{wt} \%)$ & $\mathrm{GNP}(\mathrm{wt} \%)$ \\
\hline $\mathrm{TaB}_{2}-\mathrm{SiC}$ & $89.75 \pm 1.22$ & $8.82 \pm 0.39$ & $1.43 \pm 0.32$ & 0 \\
$\mathrm{TaB}_{2}$-SiC-1GNP & $84.91 \pm 1.75$ & $13.65 \pm 0.98$ & $1.44 \pm 0.43$ & 0 \\
$\mathrm{TaB}_{2}$-SiC-3GNP & $84.04 \pm 1.78$ & $12.94 \pm 0.28$ & $1.43 \pm 0.43$ & $1.59 \pm 0.22$ \\
$\mathrm{TaB}_{2}$-SiC-5GNP & $83.32 \pm 1.24$ & $12.18 \pm 0.55$ & $1.44 \pm 0.22$ & $3.06 \pm 0.34$ \\
\hline
\end{tabular}

The patterns of SiC and graphene were not distinguishable due to the very small quantities base on the mass ratio of $\mathrm{SiC}$ and graphene in the total mass amount. In order to detect the existence of these phases, XRD analysis between $25-45^{\circ} 2 \theta$ angle range were given in Figure 5. According to the magnified view of XRD patterns, $\mathrm{SiC}$ phases were clearly seen for all samples at $2 \theta$ of $35.5^{\circ}$. Graphene peak was observed at the $26.4^{\circ} 2 \theta$ for the $\mathrm{TaB}_{2}-\mathrm{SiC}$ composites containing 3\% wt and 5\%wt graphenes whereas 
this peak did not arise in the XRD spectra for containing $1 \% \mathrm{wt}$ graphene composite (Figure 5.b.) It was considered that the quantity of graphene in the matrix was inadequate for the detectable limit for XRD spectra. In addition, it could be clearly observed that The GNPs peak intensity was increased as the content of GNPs in the composites was increased from 3 to $5 \%$.

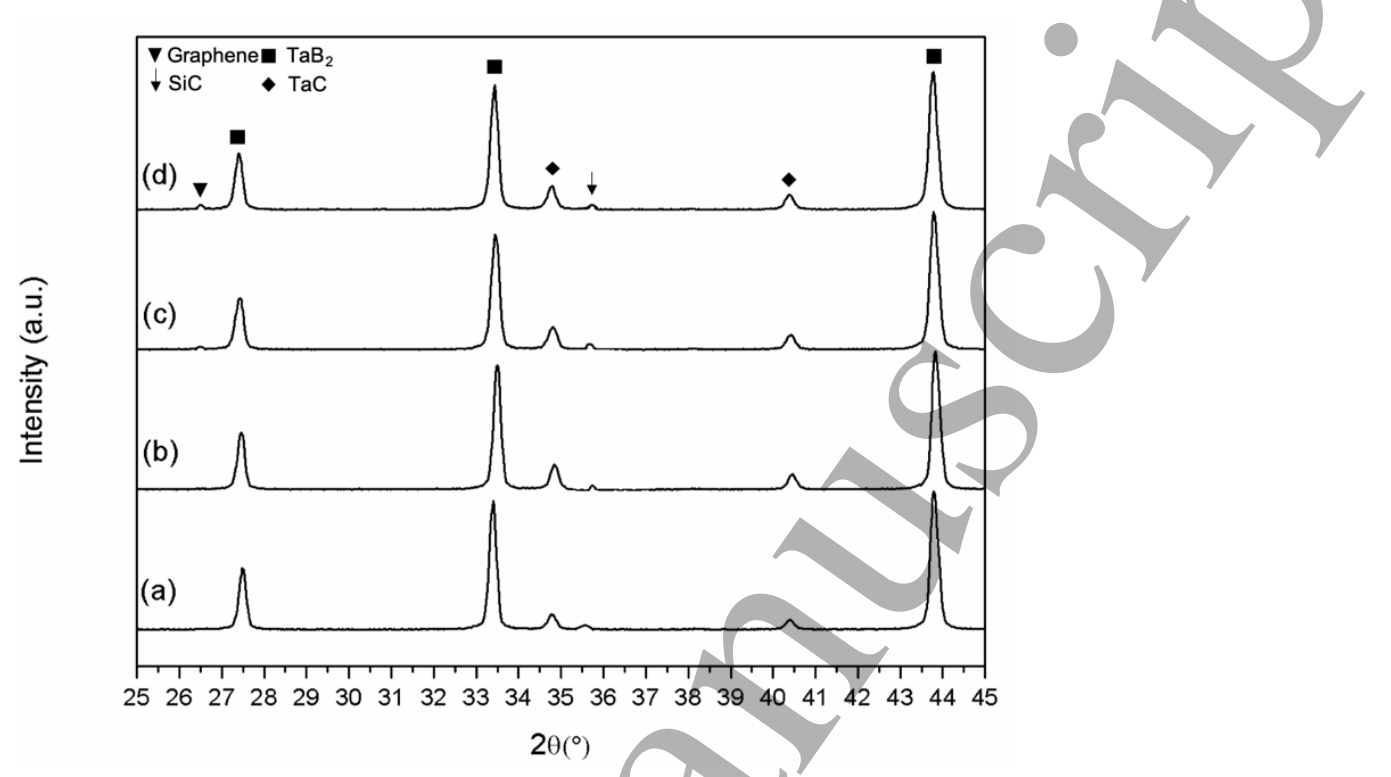

Figure 5. XRD patterns obtained from $\mathrm{SPS}^{\prime}$ ed a) $\mathrm{TaB}_{2}-\mathrm{SiC}$ b) $\mathrm{TaB}_{2}-\mathrm{SiC}-1 \mathrm{GNP}$ c) $\mathrm{TaB}_{2}-\mathrm{SiC}-$ 3GNP d) $\mathrm{TaB}_{2}-\mathrm{SiC}-5 \mathrm{GNP}$ between $25-45^{\circ}$.

\subsection{Mechanical Properties}

Hardness and fracture toughness of the $\mathrm{TaB}_{2}-\mathrm{SiC}$ and $\mathrm{TaB}_{2}$-SiC-GNPs composites were given in Table 4 and plotted in Figure 6 as a function of GNP content. The average hardness of the sintered $\mathrm{TaB}_{2}-\mathrm{SiC}$ with a relative density of $\sim 97 \%$ was $\sim 19.38 \mathrm{GPa}$. The hardness decreased from $\sim 19.38 \mathrm{GPa}$ to $\sim 17.63$, $\sim 16.66$ and 14.81 GPa with the addition of 1,3 , and $5 \mathrm{wt} \%$ GNP, respectively. The decrease in hardness could be attributed to the nature of graphene having low hardness. Moreover, it was also explained by non-uniform GNP distribution, overlapped and agglomerated of GNPs in the microstructure. This type of GNP defects caused to form a network with a weaker reinforcement effect. In addition the formation of residual stresses in the microstructure due to the thermal expansion coefficient mismatch between GNP, $\mathrm{TaB}_{2}$ and $\mathrm{SiC}$ grains lead the formation of pull out which caused a decrease in hardness. Also, mechanical polishing could lead to pull-out defects on graphene-like layered particles in the metal and ceramic matrix, so weakly bonded GNP's and $\mathrm{SiC}$ particles in the $\mathrm{TaB}_{2}$ matrix could be a reason for decreasing hardness [49]. 


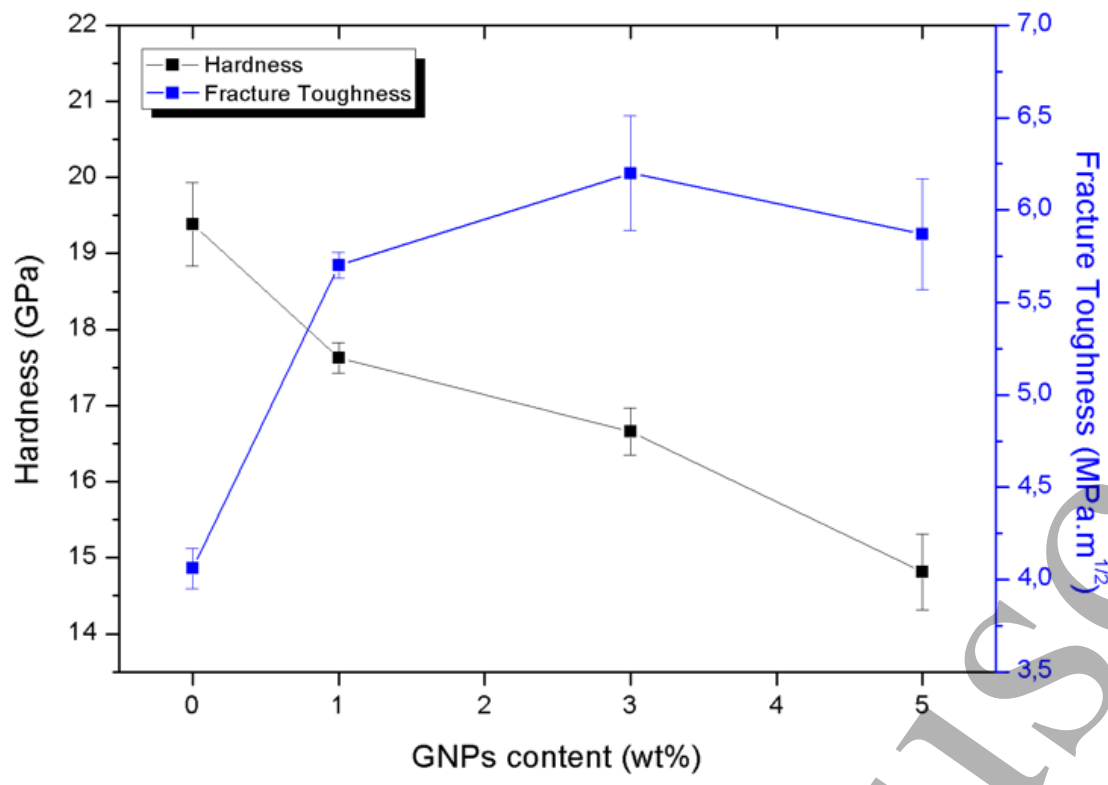

Figure 6. Changing in the hardness and fracture toughness values of sintered composites containing GNPs.

Table 4. Hardness and Fracture toughness of SPS'ed $\mathrm{TaB}_{2}-\mathrm{SiC}$ and $\mathrm{TaB}_{2}-\mathrm{SiC}$ matrix composites containing different amount of GNP

\begin{tabular}{cccc}
\hline Sample & $\begin{array}{c}\text { GNP content } \\
(\mathrm{wt} \%)\end{array}$ & $\begin{array}{c}\text { Hardness (HV10) } \\
(\mathrm{GPa})\end{array}$ & $\begin{array}{c}\text { F.Toughness } \\
\left(\mathrm{MPa} . \mathrm{m}^{1 / 2}\right)\end{array}$ \\
\hline $\mathrm{TaB}_{2}-\mathrm{SiC}$ & 0 & $19.38 \pm 0.55$ & $4.06 \pm 0.11$ \\
$\mathrm{TaB}_{2}-\mathrm{SiC}-1 \mathrm{GNP}$ & 1 & $17.63 \pm 0.20$ & $5.70 \pm 0.07$ \\
$\mathrm{TaB}_{2}-\mathrm{SiC}-3 \mathrm{GNP}$ & 3 & $16.66 \pm 0.31$ & $6.20 \pm 0.31$ \\
$\mathrm{TaB}_{2}-\mathrm{SiC}-5 \mathrm{GNP}$ & 5 & $14.81 \pm 0.50$ & $5.87 \pm 0.30$ \\
\hline
\end{tabular}

In order to measure fracture toughness values, indentation method as widely preferred for composites was used although it could not be an accurate measurement technique. The fracture toughness of $\mathrm{TaB}_{2}$ $\mathrm{SiC}$ composite was $\sim 4.06 \mathrm{MPa}^{1 / 2}$ which was comparable with the $\mathrm{TaB}_{2}$-based composites in the literature $[8,10]$. With the addition of $1 \mathrm{wt} \% \mathrm{GNP}$, fracture toughness value of $\mathrm{TaB}_{2}$-SiC composites increased by $29 \%$. Moreover $3 \mathrm{wt} \%$ GNP addition increased the fracture toughness of composite $\sim 35 \%$ to $6.20 \mathrm{MPa} \cdot \mathrm{m}^{1 / 2}$. The $\mathrm{TaB}_{2}$-SiC composite containing 3\% wt GNP exhibited the highest fracture toughness value among the measured composites as shown in Figure 6. Fracture toughness value of 5 $\mathrm{wt} \%$ GNP added sample decreased to $\sim 5.87 \mathrm{MPa} \cdot \mathrm{m}^{1 / 2}$. Although toughness value decreased from 3 to $5 \mathrm{wt} \%$ GNP addition, it was still higher $\sim 31 \%$ in comparison to $\mathrm{TaB}_{2}-\mathrm{SiC}$ composite. The decrease in 
fracture toughness was attributed to the weak interfacial bonding between matrix and GNP when the GNP content was higher than $3 \mathrm{wt} \%$.

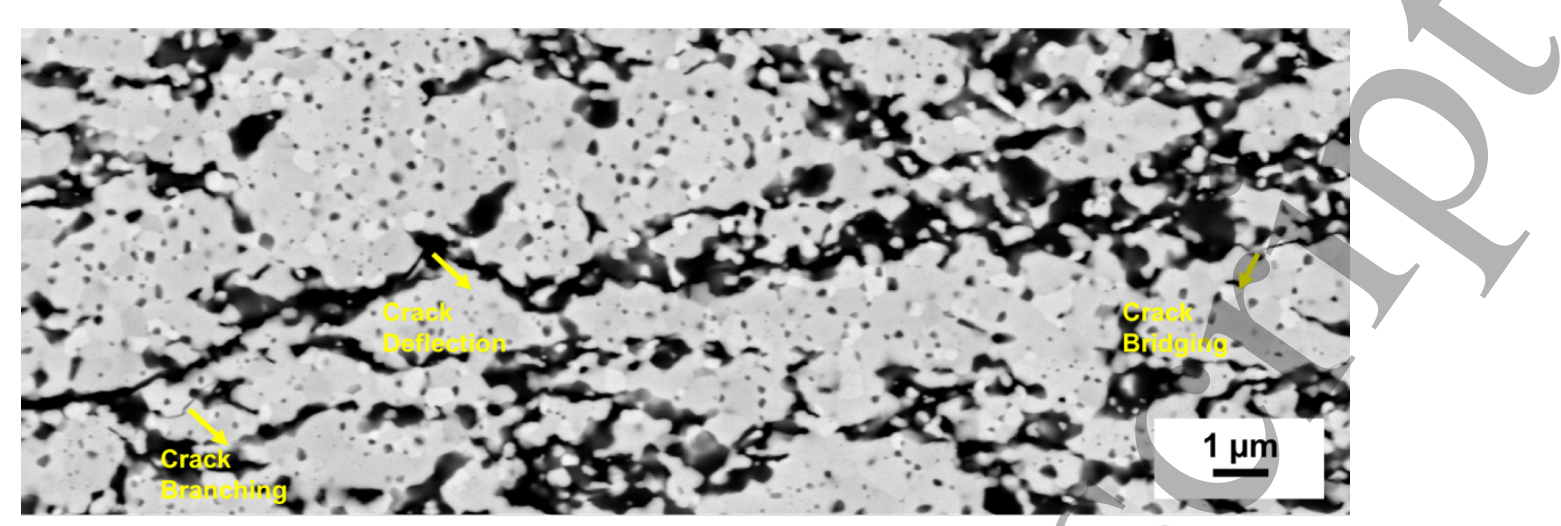

Figure 7. Crack path formed by Vicker indentation in the $\mathrm{TaB}_{2}-\mathrm{SiC}-3 \mathrm{GNP}$ composite.

The crack path created by the Vickers indentation tests for $\mathrm{TaB}_{2}$-SiC-3GNP composite was illustrated in Figure 7. It was clearly shown that crack propagation exhibited a mixed-mode from transgranular to transgranular/intergranular fracture. Crack branching at the beginning of the crack and also deflection and bridging were observed as effective toughening mechanisms due to releasing the stress of the crack tip. The cohesive strength between the matrix and GNP, amount and distribution of GNP in the matrix rose to prominence for improving mechanical properties of formed composites.

\section{Conlusions}

In this research, the effect of GNP addition on the $\mathrm{TaB}_{2}-\mathrm{SiC}$ composites on enhancement of microstructural evaluation and mechanical properties were investigated experimentally. The following were the conclusion drawn;

- 16-times repetition with microfluidization technique was more successful that other conditions for the exfoliation of GNPs.

- Density and hardness of formed composites slightly decreased with the increasing of GNPs due to the inhomogeneous distribution of GNPs in the microstructure.

- Contrary to density and hardness, fracture toughness of formed composites increased with the addition of GNPs. Addition of $3 \mathrm{wt} \%$ GNP showed optimum density, hardness and fracture toughness values.

- The crack path created by the Vickers indentation showed that crack branching, deflection, and bridging were the main toughnening mechanisms.

\section{Acknowledgement}


This study was supported by Eskisehir Technical University Research Fund with Grant no: 1501F020. The authors would like to thank Associate Prof. Dr. A.Tuğrul Seyhan and MSc. Alper Çınar for microfluidization process and Associate Prof. Dr. Feridun Ay and MSc. Merve Oper for Raman Analysis.

\section{References}

[1] J. Castaing, P. Costa, Properties and Uses of Diborides, in: V.I. Matkovich (Ed.) Boron and Refractory Borides, Springer Berlin Heidelberg, Berlin, Heidelberg, 1977, pp. 390-412.

[2] X. Zhang, G.E. Hilmas, W.G. Fahrenholtz, Synthesis, densification, and mechanical properties of TaB2, Materials Letters, 62 (2008) 4251-4253.

[3] R. Telle, Sigl, L. S. and Takagi, K., Boride-Based Hard Materials, in: R.R. (Ed.). (Ed.) Handbook of Ceramic Hard Materials, 2008, pp. 802-945.

[4] M.J. Gasch, D.T. Ellerby, S.M. Johnson, Ultra High Temperature Ceramic Composites, in: N.P. Bansal (Ed.) Handbook of Ceramic Composites, Springer US, Boston, MA, 2005, pp. 197224.

[5] W.G. Fahrenholtz, A Historical Perspective on Research Related to Ultra-High Temperature Ceramics, in: E.J.W. W. G. Fahrenholtz, W. E. Lee and Y. Zhou (Ed.) Ultra-High Temperature Ceramics, 2014, pp. 6-32.

[6] D. Sciti, L. Silvestroni, J.-L. Sans, L. Mercatelli, M. Meucci, E. Sani, Tantalum diboride-based ceramics for bulk solar absorbers, Solar Energy Materials and Solar Cells, 130 (2014) 208-216. [7] L. Silvestroni, S. Guicciardi, C. Melandri, D. Sciti, TaB2-based ceramics: Microstructure, mechanical properties and oxidation resistance, Journal of the European Ceramic Society, 32 (2012) 97-105.

[8] R. Licheri, R. Orrù, C. Musa, G. Cao, Synthesis, densification and characterization of TaB2SiC composites, Ceramics International, 36 (2010) 937-941.

[9] J. Matsushita, G.C. Hwang, K.B. Shim, Oxidation Behavior of Tantalum Boride Ceramics, Solid State Phenomena, 124-126 (2007) 819-822.

[10] S. Jun Lee, S. Baek, E. Son Kang, S. M Yong, D.K. Kim, Fabrication and oxidation behavior of reactively hot pressed TaB 2-SiC Ceramics, Reviews on Advanced Materials Science, 28 (2011) 21-25.

[11] I. Akin, G. Goller, Spark Plasma Sintering of Zirconia-Toughened Alumina Composites and Ultra-High Temperature Ceramics Reinforced with Carbon Nanotubes, in: D.B. Attaf (Ed.) Research and Innovation in Carbon Nanotube-Based Composites, 2015, pp. 85-101.

[12] G.B. Yadhukulakrishnan, A. Rahman, S. Karumuri, M.M. Stackpoole, A.K. Kalkan, R.P. Singh, S.P. Harimkar, Spark plasma sintering of silicon carbide and multi-walled carbon nanotube reinforced zirconium diboride ceramic composite, Materials Science and Engineering: A, 552 (2012) 125-133.

[13] J. Barcena, J. Coleto, S.C. Zhang, G.E. Hilmas, W.G. Fahrenholtz, Processing of Carbon Nanofiber Reinforced ZrB2 Matrix Composites for Aerospace Applications, Advanced Engineering Materials, 12 (2010) 623-626.

[14] L.S. Walker, V.R. Marotto, M.A. Rafiee, N. Koratkar, E.L. Corral, Toughening in Graphene Ceramic Composites, ACS Nano, 5 (2011) 3182-3190.

[15] K. Jankowski, P. Rutkowski, D. Kata, M. Rączka, M. Ziąbka, Microstructural analysis of aluminum nitride - GPLs composites, Ceramics International, 42 (2016) 9025-9031. 
[16] C. Yun, Y. Feng, T. Qiu, J. Yang, X. Li, L. Yu, Mechanical, electrical, and thermal properties of graphene nanosheet/aluminum nitride composites, Ceramics International, 41 (2015) 8643-8649.

[17] I.N.G. Simsek, A. Nistal, E. García, D. Pérez-Coll, P. Miranzo, M.I. Osendi, The effect of graphene nanoplatelets on the thermal and electrical properties of aluminum nitride ceramics, Journal of the European Ceramic Society, 37 (2017) 3721-3729.

[18] S. Baskut, A. Cinar, S. Turan, Directional properties and microstructures of spark plasma sintered aluminum nitride containing graphene platelets, Journal of the European Ceramic Society, 37 (2017) 3759-3772.

[19] Z. Li, J. Zhao, J. Sun, F. Gong, X. Ni, Reinforcement of Al2O3/TiC ceramic tool material by multi-layer graphene, Ceramics International, 43 (2017) 11421-11427.

[20] P. Rutkowski, P. Klimczyk, L. Jaworska, L. Stobierski, A. Dubiel, Thermal properties of pressure sintered alumina-graphene composites, Journal of Thermal Analysis and Calorimetry, 122 (2015) 105-114.

[21] Y. Yang, B. Li, C. Zhang, S. Wang, K. Liu, B. Yang, Fabrication and properties of graphene reinforced silicon nitride composite materials, Materials Science and Engineering: A, 644 (2015) 90-95.

[22] E. Bódis, O. Tapasztó, Z. Károly, P. Fazekas, S. Klébert, M. Keszler Anna, K. Balázsi, J. Szépvölgyi, Spark plasma sintering of Si3N4/multilayer graphene composites, in, Open Chemistry, 2015, pp. 484-489.

[23] P. Rutkowski, L. Stobierski, D. Zientara, L. Jaworska, P. Klimczyk, M. Urbanik, The influence of the graphene additive on mechanical properties and wear of hot-pressed Si3N4 matrix composites, Journal of the European Ceramic Society, 35 (2015) 87-94.

[24] C. Balázsi, Z. Fogarassy, O. Tapasztó, A. Kailer, C. Schröder, M. Parchoviansky, D. Galusek, J. Dusza, K. Balázsi, Si3N4/graphene nanocomposites for tribological application in aqueous environments prepared by attritor milling and hot pressing, Journal of the European Ceramic Society, 37 (2017) 3797-3804.

[25] M. Michálková, M. Kašiarová, P. Tatarko, J. Dusza, P. Šajgalík, Effect of homogenization treatment on the fracture behaviour of silicon nitride/graphene nanoplatelets composites, Journal of the European Ceramic Society, 34 (2014) 3291-3299.

[26] A. Cinar, S. Baskut, A.T. Seyhan, S. Turan, Tailoring the properties of spark plasma sintered SiAION containing graphene nanoplatelets by using different exfoliation and size reduction techniques: Anisotropic mechanical and thermal properties, Journal of the European Ceramic Society, 38 (2018) 1299-1310.

[27] G.B. Yadhukulakrishnan, S. Karumuri, A. Rahman, R.P. Singh, A. Kaan Kalkan, S.P. Harimkar, Spark plasma sintering of graphene reinforced zirconium diboride ultra-high temperature ceramic composites, Ceramics International, 39 (2013) 6637-6646.

[28] M. Shahedi Asl, M. Ghassemi Kakroudi, Characterization of hot-pressed graphene reinforced ZrB2-SiC composite, Materials Science and Engineering: A, 625 (2015) 385-392.

[29] I. Akin, O. Kaya, Microstructures and properties of silicon carbide- and graphene nanoplatelet-reinforced titanium diboride composites, Journal of Alloys and Compounds, 729 (2017) 949-959.

[30] B.C. Ocak, B. Yavas, I. Akin, F. Sahin, G. Goller, Spark plasma sintered ZrC-TiC-GNP composites: Solid solution formation and mechanical properties, Ceramics International, 44 (2018) 2336-2344. 
[31] H. Yurdakul, Y. Göncü, O. Durukan, A. Akay, A.T. Seyhan, N. Ay, S. Turan, Nanoscopic characterization of two-dimensional (2D) boron nitride nanosheets (BNNSs) produced by microfluidization, Ceramics International, 38 (2012) 2187-2193.

[32] K. Gürcan, E. Ayas, H. Gaşan, Formation of TaB2 powders from high energy ball milling and borothermal reduction process, Materials Chemistry and Physics, 235 (2019) 121732.

[33] A.G. Evans, E.A. Charles, Fracture Toughness Determinations by Indentation, Journal of the American Ceramic Society, 59 (1976) 371-372.

[34] M. Kostecki, M. Grybczuk, P. Klimczyk, T. Cygan, J. Woźniak, T. Wejrzanowski, L. Jaworska, J. Morgiel, A. Olszyna, Structural and mechanical aspects of multilayer graphene addition in alumina matrix composites-validation of computer simulation model, Journal of the European Ceramic Society, 36 (2016) 4171-4179.

[35] C.F. Gutiérrez-González, M. Suarez, S. Pozhidaev, S. Rivera, P. Peretyagin, W. Solís, L.A. Díaz, A. Fernandez, R. Torrecillas, Effect of TiC addition on the mechanical behaviour of Al2O3SiC whiskers composites obtained by SPS, Journal of the European Ceramic Society, 36 (2016) 2149-2152.

[36] D.-W. Ni, G.-J. Zhang, Y.-M. Kan, P.-L. Wang, Hot Pressed HfB2 and HfB2-20 vol\%SiC Ceramics Based on HfB2 Powder Synthesized by Borothermal Reduction of HfO2*, International Journal of Applied Ceramic Technology, 7 (2010) 830-836.

[37] B. Mehdikhani, G. Borhani, S. Bakhshi, H. Baharvandi, Effect of TaB2 on densification and hardness of tantalum carbide/boride composites, Journal of Ceramic Processing Research, 2016.

[38] T.S. Srivatsan, G. Guruprasad, M. Zelin, R. Radhakrishnan, T.S. Sudarshan, An Investigation of Carbon Content and Consolidation Temperature on Microstructure and Properties of Hafnium Boride Ceramic, Journal of Materials Engineering and Performance, 16 (2007) 757765.

[39] A. Nieto, D. Lahiri, A. Agarwal, Nanodynamic mechanical behavior of graphene nanoplatelet-reinforced tantalum carbide, Scripta Materialia, 69 (2013) 678-681.

[40] J. Dusza, J. Morgiel, A. Duszová, L. Kvetková, M. Nosko, P. Kun, C. Balázsi, Microstructure and fracture toughness of Si3N4+graphene platelet composites, Journal of the European Ceramic Society, 32 (2012) 3389-3397.

[41] A.C. Ferrari, Raman spectroscopy of graphene and graphite: Disorder, electron-phonon coupling, doping and nonadiabatic effects, Solid State Communications, 143 (2007) 47-57.

[42] J.-B. Wu, M.-L. Lin, X. Cong, H.-N. Liu, P.-H. Tan, Raman spectroscopy of graphene-based materials and its applications in related devices, Chemical Society Reviews, 47 (2018) 18221873.

[43] A.C. Ferrari, J. Meyer, V. Scardaci, C. Casiraghi, M. Lazzeri, F. Mauri, S. Piscanec, D. Jiang, K. S Novoselov, S. Roth, A.K. Geim, Raman Spectrum of Graphene and Graphene Layers, 2006. [44] A. Das, S. Pisana, B. Chakraborty, S. Piscanec, S.K. Saha, U.V. Waghmare, K.S. Novoselov, H.R. Krishnamurthy, A.K. Geim, A.C. Ferrari, A.K. Sood, Monitoring dopants by Raman scattering in an electrochemically top-gated graphene transistor, Nature Nanotechnology, 3 (2008) 210.

[45] E.H. Martins Ferreira, M.V.O. Moutinho, F. Stavale, M.M. Lucchese, R.B. Capaz, C.A. Achete, A. Jorio, Evolution of the Raman spectra from single-, few-, and many-layer graphene with increasing disorder, Physical Review B, 82 (2010) 125429.

[46] Mark Wall, The Raman Spectroscopy of Graphene and the Determination of Layer Thickness. 
[47] I. Childres, L. Jauregui, W. Park, H. Caoa, Y.P. Chena, Raman Spectroscopy of Graphene and Related Materials, 2013.

[48] K. Takai, M. Oga, H. Sato, T. Enoki, Y. Ohki, A. Taomoto, K. Suenaga, S. lijima, Structure and electronic properties of a nongraphitic disordered carbon system and its heat-treatment effects, Physical Review B, 67 (2003) 214202.

[49] C. Ramirez, L. Garzón, P. Miranzo, M.I. Osendi, C. Ocal, Electrical conductivity maps in graphene nanoplatelet/silicon nitride composites using conducting scanning force microscopy, Carbon, 49 (2011) 3873-3880. 